\title{
El giro espacial transdiciplinar, necesaria revisión de los procesos proyectuales en arquitectura: De los espacios geométricos a los espacios heterogéneos
}

\author{
The transdiciplinar turning space; necessary review of projectual processes \\ in architecture: From the geometric spaces to the heterogeneous spaces
}

$<$ Resumen>

La competencia específica señalada como la más relevante tanto por académicos, estudiantes y graduados del ámbito de la arquitectura es la «habilidad de percibir, concebir y manejar el espacio en sus tres dimensiones y en las diferentes escalas» (Tuning, 2007)**. Sin embargo, este concepto indiscutiblemente central para los arquitectos, se enfrenta actualmente a una inminente reconsideración tanto en sus estatutos epistemológicos, como ontológicos.

The most important "subject specific competence" for the architects is the ability to perceive conceive and manage space in three dimensions and on different scales (Tuning, 2007); but the idea of space itself is being redefined by the new complexity of the discipline.

<PALABRAS CLAVE>

GIRO ESPACIAL / ESPACIO ARQUITECTÓNICO / PROYECTO TUNING LATINOAMÉRICA / ARQUITECTURA AUTÓNOMA / ESPACIO KANTIANO

\section{<KEYWORDS>}

GIRO SPACE / ARCHITECTURAL SPACE / TUNING PROJECT LATIN AMERICA / ARCHITECTURE AUTONOMOUS KANT I AN SPACE
El principal concepto de la arquitectura actual desde su desarrollo moderno, el espacio arquitectónico -que define el oficio fundamental del arquitecto y su campo de acción profesional y es el eje estructurante del currículo y el elemento integrador de los demás conocimientos ${ }^{1}$ - replica un error de base adoptado por el pensamiento de la modernidad filosófica (que es su (descuidado) antecedente directo): el de la reducción del espacio a la subjetividad (tiempo) ${ }^{2}$, que hace que la arquitectura entienda como espacio lo que no es más que su herramienta proyectiva: la geometría, a la que impone como

\footnotetext{
Arquitecto Universidad de Chile. Doctor (p) Arquitectura y Urbanismo, Universidad Politécnica de Madrid / Universidad de Chile. Magister (p) e Historia del Arte, Universidad de Chile.

** El proyecto Tuning-América Latina (inspirado en la Declaración de Bologna de 1999, es la piedra angular de un profundo proceso de cambio en el sistema europeo de Educación Superior, y señala los tres objetivos fundamentales que lo orientan: movilidad, empleabilidad y competitividad), define las competencias específicas que asumirán las escuelas de arquitectura, con el objetivo central de contribuir al desarrollo de titulaciones fácilmente comparables y comprensibles, en base a los objetivos que la titulación se marque desde los perfiles buscados para los egresados, ofreciendo elementos que posibiliten ampliar la articulación entre los sistemas de educación superior de América Latina. En Chile, estimulado por Proyectos MECESUP, las escuelas de arquitectura se encuentran integrando esta modalidad de educación basada en competencias.

P. Beneitone, C. Esquetini, J. González, M. Marty, G. Siufi, R. Wagenaar. Reflexiones y perspectivas de la Educación Superior en América Latina. Informe Final -Proyecto Tuning- América Latina 2004-2007. Competencias específicas y enfoques de enseñanza, aprendizaje y evaluación. Carrera de Arquitectura. Universidad de Deusto - Universidad de Groningen, 2007.

«(...) El espacio pasa de ser lo exterior a la subjetividad (lo que no es la res cogitans) a ser lo exterior al ser. Y esto,
} tal y como reza la declaración de Foucault en nuestro exergo ${ }^{[*]}$, constituye uno de los factores más importantes 
orden rector que se reduce a abstracciones estereométricas, para su comprensión del espacio de la ciudad y de la proyectualidad arquitectónica en general.

Con ello, se inserta el tema del espacio arquitectónico en la profunda revisión que del concepto «espacio» se está operando desde diversas disciplinas filosóficas, sociales y culturales, en el llamado "giro espacial»; esto, permite actualizar la enseñanza e investigación de la arquitectura, a la indagación de herramientas espaciales, que atiendan estas nuevas conceptualizaciones y que superen su siempre inadvertida solucionática de estereometría formal-espacial; para disponerla en una problemática global reciente, de importantes consecuencias para la arquitectura, y en la que también, la arquitectura puede mucho aportar.

Desde bibliografía multidisciplinar teórica e historiográfica relevante sobre el problema del espacio; y críticos y teóricos contemporáneos de arquitectura, es posible componer el desarrollo del concepto de espacio en su operación y resultados para la arquitectura y ciudad actual. Con ello, es necesaria la indagación, por las condiciones de posibilidad que la experimentación arquitectónica actual de avanzada, tiene para afirmar una pretendida autonomía-arquitectónica-espacialdisciplinar válida, que por lo mismo, permita integrar con propiedad a la arquitectura en el diálogo y manejo multidisciplinar espacial.

Comprender críticamente (limitaciones y posibilidades) la conceptualización de base que ha constituido el desarrollo del espacio arquitectónico moderno, permite configurar para la arquitectura en símil al surgimiento de las disciplinas de conservación del patrimonio histórico, una disciplina que actúe -por ejemplo- como restauradora, que sutura fragmentos y residuos de la ciudad presente, precisamente porque es capaz de entender y reconocer espacios dañados y complejos, en su diversidad y heterogeneidad.

\section{Arquitectura autónoma}

El desarrollo de la arquitectura autónoma -cuyo germen se identifica en Boullée, Ledoux, Lequeu, arquitectos franceses de la Ilustración (Kaufmann, 1933, 1952)-, debe con radicalidad a los desarrollos que la historia y teoría del arte modernamente entendida (desde Kant), harán de los conceptos de espacio y forma. Estos dos conceptos, serán fundamentales en el desarrollo del vocabulario de las apariencias de la nueva arquitectura moderna o, por decirlo de otro modo, contribuirán a establecer las reglas generativas de tales apariencias. A saber, la Crítica de Juicio, supone el comienzo de la estética moderna, donde Kant en su formulación del juicio del gusto devela el carácter parcial del gusto estético, a la que referirán los posteriores desarrollos del concepto de la forma visual; por otro lado, el espacio, es dispuesto en la Estética Trascendental de la primera Crítica kantiana, como forma pura de la sensibilidad del sentido externo (Torretti, 2005); sin embargo, posible de reducir al tiempo o sentido interno (subjetividad, espíritu, yo, ego, o como se quiera) y en definitiva, posibilidad que la modernidad acometerá.

Así, es posible mostrar como la traducción que del concepto «espacio» hará la arquitectura moderna, y su legado contemporáneo, no es espacial sino formal (de sustrato estereométrico); y con ello, nos incorpora como arquitectos, a la revisión que del concepto de espacio se viene dando, en el curso de las últimas dos décadas, dentro de las tesis e indagaciones más relevantes del pensamiento social contemporáneo. Filósofos, científicos sociales (incluyendo notablemente a los geógrafos) y estudiosos de la cultura, han hecho parte activa, o por lo menos a lo que ha dado llamarse el «giro espacial». Este término acuñado por Jameson (1991) para referirse a la emergencia de una nueva preocupación por el espacio y las espacialidades en la posmodernidad, corresponde en términos generales, con lo que Foucault (1967) enunció en la década de 1960, como el tránsito desde una época signada por la Historia a una época del Espacio (Piazzini).

\section{De lo inclusivo \\ a lo exclusivo}

La prioridad que como competencia de manejo del espacio se otorgan hoy los arquitectos, se encontraría fundada en erróneos supuestos, que impiden en la práctica la incorporación efectiva de enfoques disciplinares diversos, en la proyección arquitectónica de la ciudad; lo que, señalemos, no se da por una deliberada mala voluntad del arquitecto que diseña, sino que, en última instancia, su adiestramiento proyectivo se funda en una forma-espacial geométrica, que opera como una estereométrica abstracta, que no atiende a las diferencias. Así, en la arquitectura el espacio es confundido con su herramienta. Los espacios de la arquitectura son concebidos como realizaciones concretas de algún espacio abstracto estudiado en geometría (elemental o compleja), que se ocupa de las relaciones de orden y magnitud entre elementos de espacios (similarmente abstractos) de diferentes estructuras, cuyos rasgos esenciales ha sido previamente necesario identificar. Cualquier posterior elemento cualificable para estas estereometrías espaciales provendrá de valores identificable con los conceptos de la forma visual, y son estas operaciones, lo que en definitiva, los arquitectos denominan espacio arquitectónico. La heterogeneidad, el principio de diferenciación, elementos constituyentes del pensamiento actual del espacio, han quedado clausurados y con ello la esfera de posibilidad de existencia de la multiplicidad (Massey, 1999).

Si las estereométricas espaciales de las ciudades y los edificios son materia de los arquitectos, en herencia neta de los postulados originales del movimiento moderno, creemos que los adiestramientos espaciales arquitectónicos, aún los más experimentales,

de inhibición de un 'pensamiento del espacio': en efecto, la reflexión sobre el espacio se ha detenido merced a dos acontecimientos contemporáneos de similar importancia; por una parte, el espacio ha sido 'ocupado' por el saber teórico experimental de la ciencia moderna (Física y Matemática) y, en la medida en que este saber se alejaba tanto del contexto del pensamiento filosófico como del 'mundo de la vida' ordinaria y del lenguaje vulgar, se ha convertido en esa idealización abstracta que no parece tener nada que ver con nosotros; por otra parte, el espacio ha sido 'ocupado' también - pero esta vez el espacio ‘de la vida'- por una serie de tácticas híbridas nacida al amparo de diferentes saberes (política, economía, urbanismo, arquitectura 'práctica', demografía, sociología, criminología, pedagogía, etc.). La dominación política y la objetividad científica se encuentran siempre sistemáticamente entretejidas». José Luis Pardo. Las formas de la exterioridad. Valencia: Pre-textos, $1992 ;$ p. 37.

${ }^{[*}$ «Podría escribirse toda una 'historia de los espacio' ...que comprendería desde las grandes estrategias de la geopolítica hasta las pequeñas tácticas del hábitat, de la arquitectura institucional, del aula o de la organización hospitalaria, pasando por las implantaciones económico-políticas. Sorprende ver cuánto tiempo ha hecho falta para que el problema de los espacio aparezca como un problema histórico-político, ya que o bien el espacio remitía a la 'naturaleza' -a lo dado, a las determinaciones primeras, a la geografía física-, es decir, a una especie de 'prehistoria', o bien se lo concebía como lugar de residencia o de expansión de un pueblo, una cultura, una lengua o un Estado. En suma, se lo analizaba como suelo o bien como aire; lo que importaba era el substrato o las fronteras... En el momento en que comenzaba a desarrollarse un política reflexiva de los espacios, las nuevas adquisiciones de la física teórica y experimental desalojaron a la filosofía de su viejo derecho a hablar del mundo, del cosmos, del espacio finito o infinito». Michel Foucault (exergo citado). 
siguen manifestando aún la idea de tabula rasa y de juegos de llenos y vacios geométricos (incluso aquellos de mirada fenomenológica, que también mostrarán su limitación). Es por esto, que aprovechando esta habilidad formada en los arquitectos, de distinciones estereométricas de llenos y vacios, se puede centrar la atención de este desarrollo ahora a sus residuos y fragmentos, lo que provee una importante necesidad de herramientas, que considere la heterogeneidad y el principio de diferenciación, en tanto, elementos constituyentes de los postulados más recientes acerca de la comprensión del espacio. Postulamos, que la arquitectura actual no cuenta con herramientas efectivas que le permitan operar con el desarrollo de los nuevos entendimientos del espacio; pues, esto conlleva comprender la hegemonía del tiempo que ha acontecido en el pensamiento moderno; y que ha definido, en definitiva, una arquitectura que entiende el espacio como estereometría fundada en la geometría (Damisch, 1981), y una apariencia constituida desde el desarrollo de la estética moderna, la cual ha perfilado su acontecer artístico en el tiempo.

\section{El influjo del espacio arquitectónico moderno}

Es F.W. Hegel el primero en disponer e espacio como tema para la arquitectura ${ }^{3,4,5}$ seducido en esta posibilidad, desde las doctrinas del espacio y tiempo kantiano de la primera Crítica6, 7 ; su continuidad, serán los desarrollo que los teóricos e historiadores del arte conllevarán, imbuidos por el hegeliano sentido de la historia, en tanto, manifestación evolutiva del espíritu que se desarrolla de manera dialéctica, y en tanto, su filosofía del arte idealista -en la que se identifica estética, historia del arte y crítica- y que no parte del valor de la imitación de la naturaleza, sino de la expresión del ideal, de la articulación entre la forma y la idea; que en definitiva, comporta una pérdida de importancia para la forma material de los objetos artísticos (y con ello, digamos, la emergencia del espacio en la arquitectura), a favor de su papel de objetos destinados a satisfacer una necesidad espiritual del hombre; llámese, el arte romántico, de la interioridad y de la subjetividad (Gombrich, 1981). En definitiva, un influjo que perfila una nueva concepción del acontecer artístico en el tiempo ${ }^{8}$, clausurando con ello necesariamente la recién inaugurada arquitectura espacial señalada.

3 «(...) Hasta donde nuestras referencias alcanzan, podemos atribuir a Hegel la posibilidad de entender la arquitectura espacialmente. A su manera de ver, la distinción de los materiales que constituyen la obra arquitectónica es un tema secundario, porque la casa y el templo implican un fin ajeno a la edificación: los habitantes -el hombre o la estatua- 'para los cuales han sido construidos'. 'Aquí -reitera- la simple diferencia entre la construcción en madera y la construcción en piedra no tiene importancia, no siendo esta diferencia relativa sino a la manera de limitar un espacio, de formar un recinto destinado a un fin religioso o humano...'.' 'Espacio semejante puede obtenerse cavando masas ya sólidas, o viceversa, construyendo murallas y techos que formen un recinto ${ }^{\prime\left[{ }^{*}\right]}$. (...) al tratar la arquitectura que denomina romántica (cuyo prototipo se halla en la gótica), propone iniciar su estudio a partir del interior de la misma, por el lugar consagrado a la reunión de los fieles, diciendo que 'el espacio interior no debe ser un espacio vació, de una regularidad abstracta...', porque las formas circulares, cuadradas, rectangulares no convendrían a los muros que determinan el recinto ni a las cubiertas. Y aunque Hegel sólo atribuye espacio a la arquitectura gótica y a la de su tiempo, desestimando cuando halla de espacial en la clásica, sus ideas fueron de importancia suma, porque abrieron los ojos a sus contemporáneos sobre este ignorado atributo de la arquitectura». José Ricardo Morales. Arquitectónica, sobre la idea y el sentido de la arquitectura. Santiago: Universitaria, 1984; p. 135

${ }^{[*]}$ Hegel, Estética. Primera sección. Arquitectura. Introducción.

«Así, desde principios del siglo xIx, aparece cierto número de escritores alemanes sobre estética que emplean el termino 'espacio' en su sentido arquitectónico moderno. El mejor ejemplo es Hegel, cuya Filosofía del Arte (basadas en las conferencias pronunciadas en 1820) contiene muchos usos del término, como cuando ser refiere a los edificios como 'limitando y cercando un espacio definido' o cuando describe una iglesia gótica como la 'concentración de la vida esencial que se autolimita en relaciones espaciales'. Esta noción en cierto modo mística de espacio se desarrollo más extensamente como técnica de crítica de arte por el historiador y critico Henrich Wölffling, y a través de sus discípulos de habla inglesa la idea se difundió en occidente». Peter Collins. Los ideales de la arquitectura moderna; su evolución (1750-1950). Barcelona: Gustavo Gili, 1988; p. 294.

«Ocurre, pues, que los contemporáneos de Hegel se dieron o rindieron cuentas muy distintas de las que éste les propuso, de ahí que hubiera de transcurrir un buen trecho de años hasta que se llegara a contar con la idea espacial antes expuesta. Kart Schnaase, que siguió a Hegel en discipulado, propone, al igual que su maestro, la distinción entre espacio interno y externo, aunque, a diferencia de aquél, considera el ámbito interno como espacio en perspectiva, (...) Konrad Fiedler analiza la arquitectura del medioevo y establece diferencias, como las de Hegel, respecto de la arquitectura antigua, por cuanto en éstas predomina la horizontal, así como en aquélla época se destacan la líneas verticales. (...) El Mismo Fiedler afirma que la arquitectura tiene por objeto 'encerrar y cubrir' espacio. Burckhardt califica al Renacimiento de 'estilo espacial', estimándolo como estilo de las relaciones entre espacio y superficie. Dehio considera en el gótico su Raumbild o ‘visión del espacio' y Schmarsow, como Riegl, ya en los umbrales de nuestro siglo, tratan la arquitectura como 'formadora de espacio' (Raumgestalterin), con la distinción Hegeliana de espacio interno y externo, o de espacio cerrado o su contorno». José Ricardo Morales. Arquitectónica, sobre la idea y el sentido de la arquitectura. Santiago: Universitaria, 1984; p. 137.

"Kant estableció que tiempo y espacio son las formas generales de la sensibilidad. Hegel adhirió, en principio a la formulación kantiana de espacio y tiempo con el agregado de que para él, el espacio es 'la primera e inmediata determinación de la naturaleza' 'la universalidad abstracta de su exterioridad'». Raúl Alberto Piérola. Hegel y la estética. Buenos Aires: Editorial Universidad Nacional de Tucumán, 1956; p. 58

En las palabras de Kant: «el espacio es la forma del sentido externo». El sentido externo es la capacidad de percibir lo que esta «afuera» de mi persona, lo que es objetivo con respecto a mí, lo que no es parte de mi ámbito interno. (...) El carácter espacial del mundo se impone por nuestras capacidades cognitivas; de allí que lo conocemos a priori. Podemos tener un concepto del mundo porque nuestra experiencia está «organizada espacialmente».

Esta sutil y aventurera visión impresionó en forma tal a Fitche, Hegel y Schopenhauer, que la incluyeron en sus sistemas (aunque después de los pequeños ajustes que requería la autoestima). Roger Scruton. Filosofía moderna. Santiago: Cuatro Vientos, 2003; p. 359.

8 «El tiempo es el principio mismo del yo = yo, de la pura autoconciencia; es el principio o el concepto simple de su compleja exterioridad y abstracción, el mero devenir intuido, el puro ser en sí en cuanto es simplemente un venir fuera de mí». La arquitectura utiliza el espacio como materia de su representación, pero lo emplea como guía del entendimiento. El espacio permanece sin espiritualizarse porque Dios está ausente de su representación artística. La escultura, a su turno, confiere al espacio una figuración orgánica donde el Espíritu particularizado y su representación exterior están en perfecta armonía. Esta coincidencia entre contenido y forma es de carácter concreto, se trasluce en una visibilidad concreta. En la pintura el espacio concreto se hace abstracto y la visibilidad se subjetiviza. Los recursos materiales de la pintura: colores, sombras, líneas son empleados como medios de expresión de lo subjetivo. Desde la arquitectura a la pintura, pasando por la escultura, se observa una expresiva idealización del espacio por el movimiento y la agilidad comunicada a la materia. La música traduce el pasaje de la sensibilidad abstracta a la espiritualidad abstracta, lo visible se torna audible. En un punto determinado el movimiento se hace fluido y el espacio resulta insuficiente para contenerlo. Hegel dice que el espacio abstracto, finito llega a un punto en que se convierte en punto de tiempo «punto negativo que es punto de separación y negación de la separación». Doble negación de la exterioridad porque el oído no se vuelca hacia los objetos externos sino percibe la vibración interior del cuerpo en el cual se asoma y revela, no la estética figura material, sino una primera idealidad proveniente del alma. El elemento sensible de la música es el tiempo. "La música, dice bellamente Hegel, es el arte donde el alma se inserta para obrar sobre las almas». (...) En la poesía encontramos que no hay límites de espacio ni de tiempo. No ofrece la precisión sensible que tiene, por ejemplo, la pintura, pero puede representar un objeto en su interioridad más íntima y en toda su explicitación temporal. Música y poesía utilizan el mismo material físico, o sea, los sonidos. Pero el sonido, en la música, tiene un fin en sí, y de ahí que sólo de un modo puramente relativo presente los movimientos del alma. En la poesía se puede decir que el elemento físico, sonoro de la palabra, se vuelve inmaterial, simbólico. La parte material queda anulada por completo o reducida a un mínimo. El Espíritu se transparenta en su propio ámbito, en intuiciones y representaciones puramente espirituales. Raúl Alberto Piérola. Hegel y la estética. Buenos Aires: Editorial Universidad Nacional de Tucumán, 1956; pp. 58-60. 


\section{El influjo de la forma arquitectónica moderna}

El desarrollo de la historia del arte y la estética en una dirección teórica y analítica, lleva para la arquitectura, desde la década de 1880, a la elaboración de un nuevo enfoque que centrará su atención en las cualidades estéticas del espacio, la masa y la forma, y en el modo en que se percibirá todo ello. «E comienzo de este proceso suele fecharse en 1886, cuando Heinrich Wölfflin ${ }^{9}$ escribió su discurso de toma de posesión, titulado Prolegomena zu einer Psychologes der Architektur (...)», pero la rehabilitación de la apariencia la había iniciado Konrad Fiedler ya en 1876. Con esta orientación más amplia, los historiadores del arte hacían hincapié en la interdependencia de la obra de arte y la Weltanschauung o visión del mundo, junto con el siempre ascendente mundo de la cultura que expresa el verbo alemán abheben, todo ello heredado de la tradición de Hegel (Tournikiotis). «Desde aquí, se contribuyó a crear el vocabulario de las apariencias de la nueva arquitectura, que omite con su enfoque esencialmente estético, la consideración de los componentes funcionales y constructivos, que posteriormente constituirán los fundamentos indiscutibles de la arquitectura moderna; sin embargo, lo que se pretendía era desde la estética la clausura de las innumerables referencias historicistas de la arquitectura, que superase el eclecticismo del siglo xIx. Por lo tanto, en lo referido a la adopción de los conceptos de forma y espacio (...) la historia del arte constituye el fundamento de la arquitectura moderna» (Tournikiotis).

\section{El espacio desde la forma en el movimiento moderno}

Las consideraciones que hará sobre el espacio la arquitectura del Movimiento Moderno, ya a inicios del siglo xx, corresponden en su desarrollo, a los principios estéticos que sobre el concepto de forma visual, desarrollara la Escuela de Viena, que surge -últimos años del siglo xix y primeras décadas de la centuria siguiente- como una brillante escuela de teóricos e historiadores del arte de importancia capital para la configuración de una ciencia del arte autónoma, independiente de la filosofía y la historia (Fiedler, von Hildebrandt, Riegl, Wölfflin, Dvorak, Wickhoff, Schlosser). La escuela de Viena se olvida del contenido, algo elemental para los positivistas, y profundiza -a través del neocriticismo kantiano- en un nuevo concepto: el de «pura visibilidad» (reine Sichtbarkeit), gracias al cual los problemas formales y perceptivos de la obra de arte irán a alcanzar una importancia desconocida hasta entonces. Específicamente para la arquitectura la extrapolación de estos postulados de sólidos fundamentos teóricos y métodos sumamente sistemáticos, serán aplicados con todo el rigor posible, pero con un enfoque más operativo para la disciplina, por tres historiadores del arte formados en Alemania Nicolaus Pevsner, Emile Kaufmann, Siegfried Giedion, los que buscarán «(...) un principio capaz de influir en la arquitectura de su propia época y del futuro inmediato, tomando para ello como criterio la percepción visual, es decir, las cualidades estéticas del espacio, la masa y la forma» (Tournikiotis). La autonomía de la obra de arte moderna adscrita a la pura visibilidad, y desde ahí, extrapolada a la arquitectura, (y con en ello al mundo de la imagen) vuelve apresurado sugerir - para nosotros- la competencia del espacio arquitectónico, como definitoria de la autonomía disciplinar ${ }^{10,11,12}$.

\section{El discutible logro del espacio en la arquitectura}

En el texto Los ideales de la arquitectura moderna (Collins, 1990), se discute la novedad y logro, de las ideas de espacio de la arquitectura moderna, indicando que las explicaciones que Henrich Wölffling da sobre el

9 «A pesar de todo, el concepto de espacio de Wölffling nunca habría conseguido su actual significado arquitectónico sino hubiera sido por los esfuerzos intuitivos de Frank Lloyd Wright. Fue él quien, a principios de nuestro siglo, por la aplicación de los nuevos materiales estructurales, explotó primero las posibilidades espaciales olvidadas desde finales del Barroco, y las aplicó a edificios apropiados a los nuevos tiempos. Estos conceptos tenían ya un precedente, pues su edificio de oficinas de Larkin (que él declaraba que era la primera expresión de este nuevo ideal) era simplemente la adaptación del interior tradicional de una iglesia a una función más moderna y materialista. Pero si comparamos el interior del edificio Larkin con su 'Unity Temple' de Oak Park (1906), con sus balcones y voladizos de hormigón armado, no sólo podemos ver una semejanza en la composición sino también la razón para conceder a este último edificio el primer puesto en la contribución de Wright a los desarrollos espaciales de la arquitectura moderna (...) Wright se centro en el 'espacio', y esto es lo que distingue a Wright de los otros grandes arquitectos de su generación (como Perret) convirtiéndole en el primer arquitecto del siglo xx. (...) Otro iniciador de la evolución moderna del espacio ha sido Ludwig Mies van der Rohe. (...) Desde la época del edificio de Larkin y el 'Unity Temple', la concepción de la arquitectura empezó a sufrir un cambio radical. Arquitectos como H.P. Berlage (que era un racionalista del siglo xix, pero profundamente influido por Wright) afirmó en un texto de 1908 (escrito, muy significativamente, en alemán) que 'el arte del arquitecto radica en esto: en la creación del espacio, no en el dibujo de fachadas'. Desde entonces, el espacio se consideró como un modelo paralelo a la estructura en la creación de composiciones arquitectónicas, y las relaciones espaciales resultantes de puntos de vista sucesivos (que había sido una característica tan importante del jardín inglés) se convirtieron en búsqueda estética principal». Peter Collins. Los ideales de la arquitectura moderna; su evolución (1750-1950). Barcelona: Gustavo Gili, 1988; p. 294.

10 «Mientras que la estetización permanece como telón de fondo cultural que penetra en mayor o menor medida en la totalidad de la sociedad actual, sus efectos serán tanto o más acusados en una disciplina que opera a través de la imagen. En este sentido, la arquitectura esta completamente atrapada dentro de esta condición, porque los arquitectos se vinculan con el proceso de estetización como una consecuencia necesaria de su profesión. (...) El mundo del arquitecto es el mundo de la imagen (...) Las consecuencias de todo esto son notables. Este privilegio de la imagen ha llevado a un empobrecimiento en el entendimiento del ambiente construido, convirtiendo el espacio social en un fetiche abstracto. El espacio de la experiencia vital ha sido reducido a un sistema codificado de significación, y con el creciente énfasis de la percepción visual se ha producido la correspondiente reducción de otras formas de percepción sensitiva. 'La imagen mata', como ha escrito Henri Lefebvre, y no da cuenta de la riqueza de la experiencia vital (...) la separación entre prácticas espaciales y representaciones del espacio es total». Neil Leach. La an-estética de la arquitectura. Barcelona: Gustavo Gilli, $2001 ;$ p. 28.

11 «El acontecimiento fundamental de la edad moderna es la conquista del mundo como una imagen», escribe Heidegger. (...) Hoy en día el ojo tecnológicamente expandido y fortalecido penetra profundamente en la materia y en el espacio y permite al hombre mirar simultáneamente a los lados opuestos del globo. Las experiencias del espacio y el tiempo han pasado a fundirse una con otra mediante la velocidad (David Harvey utiliza el concepto de "compresión espacio-temporal») y, en consecuencia, estamos siendo testigos de una clara vuelta a las dos dimensiones; a una temporalización del espacio y a una espacialización del tiempo. La vista es el único sentido lo suficientemente rápido como para seguir el ritmo del increíble incremento de la velocidad en el mundo tecnológico.

(...) En opinión de Heidegger, la hegemonía de la vista en un primer momento suscitó visiones gloriosas, pero se fue volviendo más nihilista en los tiempos modernos. La observación de Heidegger sobre el ojo nihilista da mucho sobre lo que reflexionar hoy en día; mucho de los proyectos arquitectónicos de los últimos veinte años, celebres gracias a la prensa especializada internacional, expresan tanto narcisismo como nihilismo.

(....) El ojo hegemónico trata de dominar todos los campos de la producción cultural y parece debilitar nuestra capacidad para la empatía, la compasión y la participación en el mundo.

Juhani Pallasmaa. Los ojos de la piel. Barcelona: Gustavo Gili, 2006; pp. 20-21.

12 «Al igual que el ojo del arquitecto, nada hay más inocente que el solar que se le da al arquitecto para construir, o que la hoja de papel en blanco donde dibuja su primer boceto. Su espacio ‘subjetivo' esta cargado de significados demasiados objetivos. Es un espacio visual, un espacio reducido a copias, a meras imágenes, a ese 'mundo de la imagen' que es el enemigo de la imaginación». Henry Lefebvre. The production of space. Cambridge: Blackwell, 1974. 
espacio arquitectónico, son en referencia, más bien a la pintura de un interior arquitectónico, más que al mismo interior arquitectónico; o las extrapolaciones que Sigfried Giedion dará de las experiencias espacio-tiempo de la arquitectura, son derivadas del espacio-tiempo de Einstein o de las teorías de Oswald Spengler (y que nada tienen que ver con nosotros); Frank Lloyd Wright, quien primero acusara la nueva intención espacial lo hará con la aplicación de nuevos materiales estructurales y el uso de balcones y columnatas hongo que se mantienen por sí solas; Ludwig Mies van der Rohe desde su experiencia del diseño de pabellones; Le Corbusier desde su influencia cubista; Aguste Perret con su énfasis en los puntos de soportes aislados; Louis Kahn con la introducción de torres altas, que cambian al moverse en torno al edificio, etcétera. Con ello, el modo de entendimiento del espacio que ha pretendido la arquitectura moderna, y su herencia actual, puede no haber hecho más que descubrir un mediterráneo en exceso frecuentado (...), sugeriría que los efectos visuales a los que normalmente nos referimos como Espacio-Tiempo, cuarta dimensión, etcétera, «no son ni más ni menos que evoluciones modernas de la explotación de los efectos de paralaje» (...) el fenómeno de paralaje «por el que se produce un desplazamiento aparentes de objetos cuando el punto de observación cambia», es también, como el Espacio-Tiempo, un aparato para medidas astronómicas, pero, al revés que el Espacio-Tiempo, ha sido un elemento importante en la composición arquitectónica, y ha sido conocido en arquitectura desde que se construyo la primera sala hipóstila (Collins, 1988).

\section{El giro espacial como posibilidad para la агquitectura}

La modernidad ha privilegiado el tratamiento del tiempo respecto del espacio en el pensamiento occidental, por lo menos desde Kant hasta Heidegger (Foucault 1967, Soja 1994, Harvey 1998, Pardo 1992). Ello habría determinado la precariedad ontológica y la distribución epistemológica de lo espacial en las ciencias modernas, derivando en el tratamiento accesorio o secundario que el espacio y las espacialidades han recibido específicamente dentro de las ciencias sociales. El diseño arquitectural de espacios, en este sentido, ha operado bajo un supuesto de espacialidad no tematizado, pero homogéneamente aceptado, que ha constituido -querámoslo o no- nuestras formas de habitabilidades modernas ${ }^{13,14}$. Superar los modos de considerar el espacio en la arquitectura, como un contenedor físico (estereometrías) en que se derraman las actuaciones sociales o como expresiones plásticas de algo más esencial (subjetividades) dispone a trazar una arquitectura critica, atenta a las diferentes formas de espacialidad que contribuyen a configurar lo social (con ello su necesaria comunicación disciplinar), pero al mismo tiempo, el más grande esfuerzo en desarrollar e investigar la arquitectura en su más radical posibilidad: como «espacialidad arquitectónica» que en definitiva, nos constituye en gran medida las referencias comunes al espacio físico en que nos movemos, vivimos y somos, como habitantes de la ciudad.
El manejo que la arquitectura dice tener del "espacio» es un supuesto del todo asumido, que ha sido entendido -en gran medida- de modo a-crítico ${ }^{15}$; por ello su consideración debe recibir algún tipo de resguardo teóricohistórico-filosófico, en tanto, los arquitectos deben estar llamados cada vez más a sumarse a intervenir en debates sobre los valores de la sociedad contemporánea. Actualizar el entendimiento sobre el «espacio» en arquitectura, implica hurgar en los desarrollos filosóficos-estéticos que le han dado lugar, para comprender precisamente lo más paradójico, que es la carencia de lo «espacial» que hay en ello. Es por esto, que este concepto definido como central para los currículos y formación de los arquitectos, debe ser revisado, y con ello, las actuales reformas curriculares universitarias -que ni si quiera enteran dichos cambios- deben atender las conceptualizaciones de base, que emergen de dichas consideraciones, pues, el espacio en arquitectura es un cambio que atiende, a surgencias de mayor complejidad, referido a un modo diferente de pensamiento, respeto de la racionalidad moderna.

Nuestra comprensión de la noción de espacio en arquitectura en su desarrollo moderno, entonces, es plausible sintetizar como geometría (espacio) y visualidad (forma). Nuestro problema no va con ellos, sino que reconoce aquellos como una interpretación posible, que conforma una profunda síntesis representacional, que logra identificarse a transformadoras concepciones epistemológicas de lo moderno, tanto, en lo científico como en

13 «Otra de las dificultades existentes para superar el desfase entre el arquitecto y el profano, así como entre los propios arquitectos, es la falta de una terminología precisa. El confuso debate entre los temas arquitectónicos es una demostración del uso impreciso del lenguaje y de enunciados sin sentido. Esta terminología inconcreta se suma al desorden y dificulta las discusiones profundas incluso entre los propios arquitectos ${ }^{\left[{ }^{*}\right.}$.

${ }^{[\star]}$ «Nos referimos ante todo al uso de la palabra 'espacio' que se emplea sin aclarar si se hace referencia a un espacio físico o psicológico, o quizás a una entidad metafísica indefinible».

Norberg-Schulz Ch. Intenciones en arquitectura. Barcelona: Gustavo Gili, 2001; pp. 14, 146.

14 «El espacio! Una palabra con tal atractivo mágico para el arquitecto del siglo xx, una palabra tan empleada (y mal empleada) que comencé a preguntarme de dónde provendría y qué podría significar. Escuchando a mis maestros, les oí emplear la palabra 'espacio' con diversas entonaciones y, al principio de los libros sobre arquitectura, tal concepto suele ser presentado como el alfa y omega de la misma. Y, finalmente, cuándo comencé a diseñar, tuve la excitante impresión de haber topado con el concepto más misterioso e intangible de la arquitectura: el espacio». Cornelis van de Ven. El espacio en arquitectura: la evolución de una idea nueva en la teoría e historia de los movimientos modernos. Madrid: Cátedra, 1977; p. 11

15 «Puestos a explicar la naturaleza de sus trabajos y sobre todo la materialidad que los proyectos tratan de alcanzar, los arquitectos no pueden eludir pasar por el espacio; (...) Esto no quiere decir que los arquitectos se pregunten por la noción o la idea que ellos tienen de ese espacio, por el contrario, la asumen como parte de aquello que les ha sido dado y frente a lo cual no poseen las herramientas que permitan su transformación, se dice incluso en muchos niveles que los arquitectos no tienen nada que decir al respecto pues no están preparados para enfrentar el tema y deben usar el espacio ni más ni menos que de la misma manera en que usan el agua, el aire, o el concreto, el espacio es sólo un material de trabajo que más que preguntado ha de ser descrito y detallado como si fuese sólo una materia más de trabajo.

Pero no es así; el espacio no es como cualquier cosa y por ello siempre, de alguna manera, que no es de cualquier manera, el arquitecto tiene que tomar posición, con respecto a este escurridizo tema, algún tipo de posición.

El problema del espacio puede llegarle a través de la discusión sobre la ciudad, sobre sus características o sobre cómo se constituye un espacio arquitectónico, sobre el uso del suelo, o sobre las áreas óptimas para tal o cual función. Frente a interrogantes de este tipo el arquitecto suele decir que responde a través de su trabajo, pero, iy si su trabajo fuese precisamente definir ese espacio? ¿No estaría obligado a decir algo más sobre él? $\mathrm{O}$ al menos ¿no estaría obligado a demostrar que es algo más que un empleado eficiente de las ideologías de turno?». Ruth M. Díaz Guerrero. El espacio público como escenario, cinematográfico, la arquitectura como obscenidad. Tesis Doctoral. Universidad Politécnica de Cataluña, Barcelona. 
Io filosófico ${ }^{16}$. Sin embargo, y dentro de su afán autonómico, la arquitectura -como espaciono logra sustentar (en su concepción espacioformal) una especificación afirmativa de su particularidad o mejor dicho de su diferencia. Comenzar aquello será para nosotros, considerar «el espacio donde se mueven nuestros cuerpos» y que es precisamente el toque para la arquitectura, y a la vez pensamos un necesario artificio.

Al interrogar la noción de espacio en arquitectura, se pretende precisamente reafirmar la arquitectura como problema espacial, pensándola dentro de un ámbito que omite el registro de la representación, y la dispone en un problema que asuma en su radicalidad el espacio de los cuerpos como condición de posibilidad para la arquitectura ${ }^{17}$. Pues, en el modulor corbuseriano sólo hubo mensura, pero nunca afección. Entonces, nunca hubo cuerpo y con ello nunca hubo espacio.

\section{Conclusión}

La idea de espacio en arquitectura, es un concepto de no larga data en la disciplina y que ha sido fundado, merced a una cierta voluntad de autonomía en las artes; su incorporación en la arquitectura, es una síntesis de ideas diversas, que han conjugado un rol clave para sustentar un cierto relato de hacer arquitectónico, dado en la arquitectura denominada Moderna. El análisis crítico de la(s) idea(s) de espacio en arquitectura, permite dilucidar (o recordar) la historicidad que han conformado su desarrollo en el tiempo (lo cual es válido, también, para toda idea). Sin embargo, pensar el espacio para la arquitectura (creemos), pudiese 0 debiese nombrar o afirmar algo más que una idea entre otras, en la medida en que se reconozca la condición arquitectónica como ligado a un pensar (o sentir) diferente, que reconoce el abismo existente entre lo material y lo conceptual; y con ello, la puesta en paréntesis del enfrentamiento consciente a la obra, que supone la experiencia subjetiva en que se piensa o imagina la obra de arte brindada al espectador (e incluso la idea de espectador pudiese omitirse en beneficio de los habitantes).

El pensamiento del espacio -como se han reseñado sus acontecimientos- ha sido inhibido, dentro del desarrollo del pensamiento adoptado por la modernidad occidental. En este sentido, la reflexión sobre el espacio no ha acontecido (en el sentido en que nos importa), en tanto, ha sido ocupada por el saber teórico-experimental de la ciencia moderna (física y matemática); y marginado como lo exterior a la subjetividad y por ello a ser lo exterior al ser, para la filosofía. La arquitectura ha insertado su desarrollo o caracterización espacial (entendida acá como pensamiento y no como obras [en tanto, falta aún patentizar el abismo que existe en esto]) dentro de ciertas concepciones simbólicas híbridas de aquéllos, pero más aún, como supuesto del todo asumido para su operar disciplinar. Pensar el espacio de (y luego, para) nuestros cuerpos (que es el que nos importa), no es pensar en mensuras, ni experiencias subjetivas, ni tampoco objetivas; sino que es disponer nuestro pensamiento de modo tal, que no podamos pensar lo que nos sucede, en términos de modulación del mismo mundo ni del mismo sentido ${ }^{18}$. Consideremos: Los campos en que se yuxtaponen las sensaciones no pueden confundirse con el espacio en que se mueven los cuerpos $^{19}$; y por eso, que disponer a la arquitectura dentro de su entendimiento de lo espacial, y ligada inextricablemente a esta condición, no pasa por la espacialidad de un cuerpo individual (plausible de reducir a alguna subjetividad) sino que de los cuerpos, comprendidos en su mutua afectabilidad y con ellos su exterioridad ${ }^{20}$. Esto que en este trabajo no busca ser establecido ${ }^{21}$, implica

16 «( ) muy frecuentemente la definición de espacio no se da de modo explicito dentro de cada una de las teorías sino que esta implícita y debe deducirse a través del análisis critico y filológico (. ) También hay que partir de la base de que un análisis totalmente arquitectónico del termino 'espacio' no podrá ciertamente prescindir de la referencia a las definiciones de espacio, por así decir, extradisciplinares; en efecto, en el término espacio parece concretarse uno de esos puntos de paso, de esos lazos que conectan en la unidad del pensamiento los momentos del conocimiento disciplinar con los más generales del conocimiento científico, con la teorética filosófica del espacio y con la historia empírico-antropológica de la percepción espacial.

Es evidente en efecto que se estará próximo a definir el espacio 'arquitectónico' si se le distingue del espacio entendido en sentido científico-filosófico (...); igualmente es evidente, por otro lado, lo peligroso de distinguir mecánicamente en ramas especializadas (filosóficas, científicas, artísticas, etc.), el concepto de espacio». Ludovico Quaroni. Proyectar un edificio, ocho lecciones de arquitectura. Madrid: Xarait, 1987; p. 91

17 «Si hubiera sido más fácil entender el cuerpo, nadie habría pensado que teníamos una mente». Richard Rorty. En: Juhani Pallasmaa. Los ojos de la piel. Barcelona: Gustavo Gili, 2006; p. 14

18 «Platón pretende que un discurso tenga el cuerpo bien formado de un gran animal, con cabeza, vientre y cola. Por ello nosotros, buenos y viejos platónicos, sabemos y no sabemos lo que es un discurso sin cola ni cabeza, sin falo y acéfalo. Sabemos: es el sin-sentido. Pero no sabemos: no sabemos qué hacer con el 'sin sentido', no conseguimos ver más allá del extremo del sentido.

Siempre le hacemos señas al sentido: más allá, perdemos pie ( . . .

'El cuerpo' es donde se pierde pie. 'Sin-sentido' no quiere decir aquí algo parecido al absurdo, ni tampoco el sentido a la inversa, o contorsionado como se quiera (no es en Lewis Carroll donde se tocarán los cuerpos). Pero esto quiere decir: no hay sentido, o incluso, sentido, sí, pero al que está absolutamente excluido acercarse bajo ninguna figura de 'sentido'. Sentido que tiene sentido allí donde es, para el sentido, límite. Sentido mudo, cerrado, autístico: pero precisamente no hay autos, tampoco 'sí mismo'. El autismo sin autós del cuerpo, lo que lo hace infinitamente menos que un 'sujeto', pero también infinitamente otra cosa, arrojado, yecto, no 'sub-yecto', pero tan duro, tan intenso, tan inevitable, tan singular como un sujeto. (...) Cuerpo impotente e ininteligente. Sus posibles están en otra parte, sus fuerzas, sus pensamientos.

Pero 'impotente' e 'ininteligente' son aquí palabras impotentes e ininteligentes. El cuerpo no es ni estúpido, ni impotente. Le convienen otras categorías de fuerza y de pensamiento». Jean-Luc Nancy. Corpus. Madrid: Arena, 2003; p. 14.

19 «(...) no es preciso calar tan hondo para darse cuenta de que el espacio de que habla Kant no es uno de estos espacios de los sentidos, como el llamado campo visual u otro medio más amplio del que este fuera un aspecto. En efecto, si Kant entendiera por espacio la extensión en que se despliegan naturalmente nuestras sensaciones, la doctrina kantiana que liga el espacio a nuestra facultad representativa sería una perogrullada. Como es obvio el campo visual no existe, como tal aparte de nuestra vista. Ni las manchas de color fuera del campo visual. Pero no es menos obvio que de tales trivialidades no se puede inferir que los cuerpos cuya presencia exhiben esas manchas no existen como cuerpos independientemente de nuestras representaciones sensibles de ellos. ( . ) Los campos en que se yuxtaponen las sensaciones no pueden confundirse con el espacio en que se mueven los cuerpos. Y éste (...) es el tema de las meditaciones de Kant». Roberto Torretti. Manuel Kant, estudio sobre los fundamentos de la filosofía crítica. Santiago, UDP, 2005; pp. 97-98.

20 «Que el 'cuerpo' nombre al Extraño, absolutamente, tal es el pensamiento que hemos llevado a buen fin (...) (Se nos ocurre que, a esta palabra, sólo se la salva con bellos dibujos de geometría de tres o de n dimensiones, con elegantes axonometrías: pero entonces todo flota suspendido en el aire, y el cuerpo debe tocar tierra)». Jean-Luc Nancy. Corpus. Madrid: Arena, 2003; p. 11.

21 «No obstante, del cuerpo con el que el yo forma 'una sola entidad', del cuerpo que piensa en el acomodaticio sentido que Descartes da a la expresión en la Sexta Meditación, probablemente conocemos muy poco más de lo que los griegos conocían. ( ) Del cuerpo como un objeto o una cosa nosotros conocemos, por supuesto, muchísimo más de lo que conocieron o pudieron haber conocido los griegos, y nuestras creencias sobre él están en constante transformación, como lo están nuestras creencias sobre el mundo mismo, del cual el cuerpo como objeto forma parte. (...) Hay una verdad innegable en el comentario de Heidegger de que, en lo tocante a las emociones, no hemos dado un solo paso más allá de Aristóteles en dos mil años». Arthur Danto. El cuerpo/el problema del cuerpo. Madrid: Síntesis, 1999; pp. 243-246. 
primeramente una des-obra de la disciplina arquitectónica frente a la obra económica, técnica e institucional y con ello, indagar en sus condiciones de posibilidad; superando la relación de lo espacial de la arquitectura, con su suerte de desentendimiento de lo espacial, que concluye, en definitiva, irremediablemente, en procedimientos de resolución de proyectos.

Sostenemos que el espacio de los cuerpos es el espacio de toque para la arquitectura y precisamente condición para pensar una autonomía disciplinar espacial. Pensar con y desde Kant este espacio de los cuerpos permite comprender, la posibilidad acometida por la modernidad filosófica, de reducción de lo espacial al tiempo (posibilidad que Kant, precisamente no acometió); pero sobre todo, el espacio como condición de posibilidad de lo externo, que convoca precisamente la pregunta por la Exterioridad, como irreducible a la subjetividad, y que permite para la arquitectura trabajar (en la medida en que se interese en el espacio de los cuerpos) en el encuentro a una ajenidad que la toca.

\section{Bibliografía}

Giulio Argan. El concepto de espacio arquitectónico, desde el Barroco a nuestros días. Buenos Aires: N. Visión, 1973.

Esquetini Beneitone, Marty González, Wagenaar Siufi. Reflexiones y perspectivas de la Educación Superior en América Latina.
Informe Final -Proyecto Tuning- América Latina 2004-2007. Competencias específicas y enfoques de enseñanza, aprendizaje y evaluación. Carrera de Arquitectura, Universidad de Deusto. Universidad de Groningen, 2007

Peter Collins. Los ideales de la arquitectura moderna: Su evolución (1750-1950). Barcelona: Gustavo Gili, 1991.

Hubert Damisch. Ledoux con Kant (prólogo a la traducción francesa). En: Emil Kaufmann. La arquitectura de la Ilustración. Barcelona: Gustavo Gili, 1955.

K Fiedler. Escritos sobre arte. Madrid: Visor, 1990.

Michel Foucault. El pensamiento del afuera. Valencia: Pre-textos, 2000.

Michel Foucault. Las palabras y las cosas. Una arqueología de las ciencias humanas. Buenos Aires: Siglo XXI, 2003.

E.H. Gombrich. Ideales e ídolos. Ensayo sobre los valores en la historia y en el arte. Barcelona: Gustavo Gili, 1981.

E.H. Gombrich. Tributos. Versión cultural de nuestras tradiciones. México D.F.: Fondo de Cultura Económica, 1991.

David Harvey. La condición de la posmodernidad. Investigaciones sobre los orígenes del cambio cultural. Buenos Aires: Amorrotu, 1998.

G.W. Hegel. Lecciones de estética. Barcelona: Alta Fulla, 1988.

Fredric Jameson. El posmodernismo o la lógica cultural del capitalismo avanzado. Barcelona: Paidós, 1991.

Max Jammer. Conceptos de espacio. México D.F.: Grijalbo, 1970
Inmanuel Kant. Crítica de la razón pura. Madrid Alfaguara, 2003

Inmanuel Kant. Crítica del juicio. Buenos Aires: Losada, 1993.

Emil Kaufmann. La arquitectura de la Ilustración. Barcelona: Gustavo Gili, 1955.

Emil Kaufmann. Tres arquitectos revolucionarios: Boulléeu, Ledoux y Lequeu. Barcelona: Gustavo Gili, 1980.

Doreen Massey. Negotiating disciplinary boundaries. Currente Sociology; 47(4).

Pablo Oyarzún. Anestética del Ready Made. Santiago: LOM, 2000.

José Luis Pardo. Las formas de la exterioridad. Valencia: Pre-textos, 1992

Carlo Piazzini. El tiempo situado: Las temporalidades después del giro espacial. Medellín: Antioquía, 2004.

Nikolaus Pevsner. Pioneros del diseño moderno: De Williams Morris a Walter Gropius. Buenos Aires: Infinito, 1958.

Edwards Soja. Postmodern geographies: The reassertion of space in critical social theory. Nueva York: Verso, 1994.

Roberto Torretti. Manuel Kant, estudio sobre los fundamentos de la filosofía crítica. Santiago: UDP, 2005

Panayotis Tournikiotis. La historiografía de la arquitectura moderna. Madrid: Mairea, 2001.

H. Wölfflin. Conceptos fundamentales de la historia del arte. Madrid: Espasa, 1985. 